06

\title{
Влияние кулоновских сил на процессы роста золота на поверхности диэлектрических подложек
}

\author{
(ㄱ В.П. Власов, А.Э. Муслимов , В.М. Каневский \\ Институт кристаллографии им. А.В. Шубникова ФНИЦ „Кристаллография и фотоника“ РАН, Москва, Россия \\ E-mail: amuslimov@mail.ru
}

Поступило в Редакцию 6 июля 2018 г.

В окончательной редакции 7 декабря 2018 г.

Принято к публикации 10 декабря 2018 г.

\begin{abstract}
Рассматривается модель взаимодействия наноостровков золота при осаждении из пара в вакууме при наличии зарядов и при их удалении из пара. Установлена стадия роста (средняя толщина осадка $>2 \mathrm{~nm}$ ), на которой наблюдаются взаимное притяжение наноостровков золота и резкое увеличение их размеров. Осадок, из которого удалены заряды, показывает замедление роста наноостровков на этой стадии. Продемонстрировано влияние геометрического рельефа подложки на морфологию осадка. Представленные исследования перспективны для развития методов сегментации нанопокрытия и формирования упорядоченных ансамблей наноостровков.
\end{abstract}

DOI: 10.21883/PJTF.2019.05.47394.17455

Развитие нанотехнологий неразрывно связано с необходимостью контролируемого формирования наноструктур, образованных из наноостровков, путем их упорядочения, сборки. Такой подход может лечь в основу создания наноматериалов, обладающих уникальными свойствами по сравнению с традиционными микрообъектами [1-3]. Однако требуемого уровня воспроизводимости в производстве наноструктур не достигнуто. Связано это с влиянием большого число параметров на размеры растущих наноостровков и их плотность распределения. Среди основных факторов, которые учитываются при построении различных моделей, отмечаются обычно следующие: реальная структура поверхности подложек и ее температура; скорость поступающих на подложку атомов и молекул и их направление к подложке; степень вакуума во время осаждения атомов и молекул, т.е. влияние остаточных газов. Используемая на протяжении длительного времени феноменологическая теория зародышеобразования [4], т.е. образования наноостровков из пара, исходит из того, что конденсирующиеся на подложке атомы образуют двумерный газ, который является основой образования скоплений атомов. Эта теория развивается вплоть до настоящего времени [5]. Со справедливостью такого подхода трудно согласиться, поскольку к содержащим незначительное количество атомов наноостровкам макроскопическая термодинамика неприменима. Критическая температура, выше которой не будут разрастаться первичные зародыши, экспериментально не была установлена. В атомистической модели [6] энергетика образования наноостровков трактуется с точки зрения магнитных сил и энергии активации поверхностной миграции. Существует ряд полуэмпирических подходов [7], основанных на определении атомов осадка в относительных минимумах потенциала поверхности. Они базируются на предположении атомарно-гладкой поверхности и объясняют, как правило, только частные эксперименты.

С развитием высокоскоростной техники обработки информации появилась возможность реализовать теоретические методы для оценки размеров и поверхностной плотности распределения наноостровков. Они делятся на две группы: аналитические методы [8], основанные на решении уравнения диффузии, и численное моделирование [9] поведения индивидуального наноостровка на подложке. Как показывает практика, точность результатов, получаемых с применением этих методов, ограничивается тем же основным недостатком, связанным с необходимостью вводить в рассмотрение большое число параметров.

Подводя итог, следует отметить, что во всех моделях пренебрегается электростатическим взаимодействием диффундирующих наноостровков как между собой, так и с неоднородностями рельефа. На наш взгляд, недостаток такого подхода проявляется как в понимании процессов формирования островковой структуры осадка, так и в возможности управления этим процессом. В [10] приводятся данные о том, что геометрический рельеф поверхности подложки влияет на морфологию покрытия.

В настоящей работе рассматривается влияние электростатических сил на начальные стадии роста осадка в системах, включающих диэлектрические кристаллы $\left(\mathrm{KCl}, \mathrm{Al}_{2} \mathrm{O}_{3}\right)$ в качестве подложек и благородный металл (золото) в качестве покрытия. Выбор таких систем обусловлен легкостью получения чистой поверхности щелочно-галоидных кристаллов сколом по поверхности спайности и отработанным методом формирования атомно-гладкого периодического рельефа на поверхности сапфира [11]. Благородные металлы химически не взаимодействуют с этими подложками, и их легко напылять методом сублимации в вакууме в контролируемых условиях. 

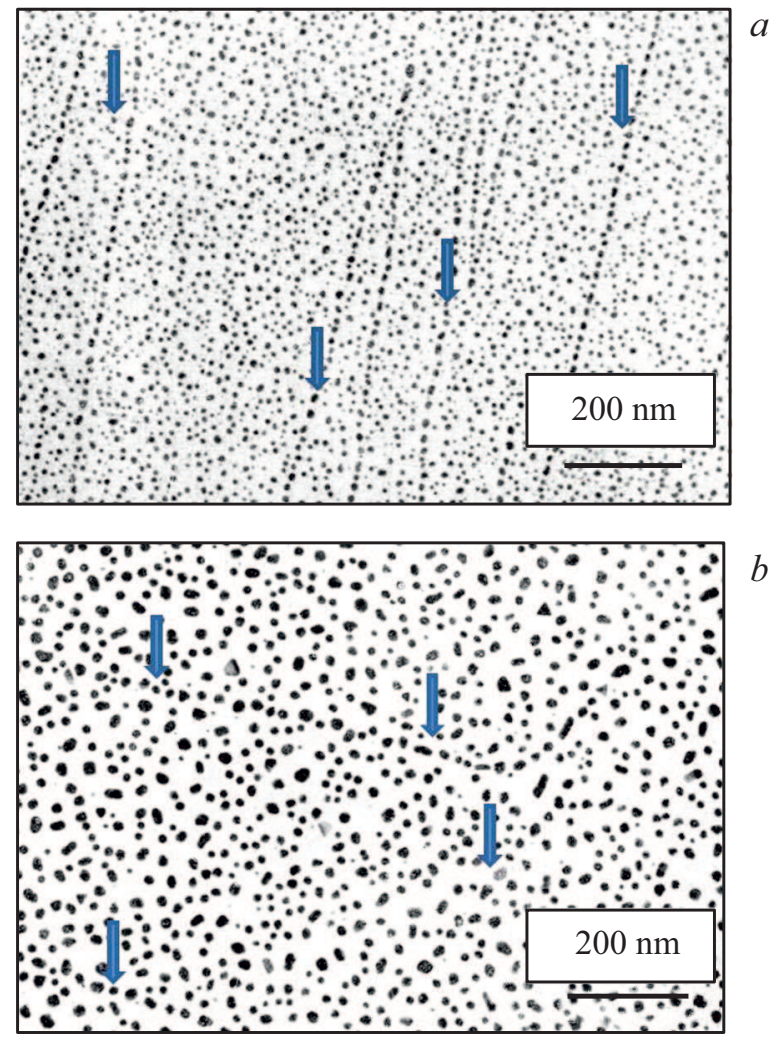

Рис. 1. Электронно-микроскопические изображения осадка золота на поверхности свежего скола (001) кристалла хлористого калия при $T=470 \mathrm{~K}$ и средней толщине слоя $\sim 3.5 \mathrm{~nm}$ (скорость осаждения $\sim 1 \mathrm{~nm} / \mathrm{min}$ ). $a-$ при удалении из потока пара ионов, $b-$ при наличии ионов. Стрелками отмечены ребра ступеней свежего скола хлористого калия.

Осаждение золота на подложки проводилось в установке, откачиваемой до вакуума $10^{-6} \mathrm{~Pa}$. Толщина слоя и интенсивность потока испаряемого золота измерялись кварцевыми резонансными микровесами на частоте $\sim 5.5 \mathrm{MHz}$. Ионы из потока пара отклонялись конденсатором, к обкладкам которого прикладывалось напряжение $\pm 100 \mathrm{~V}$. Отклоняемые ионы попадали на умножитель, измерялись прибором счета ионов. Было установлено, что заряд несет порядка 1 атома из 1000 и зависит от температуры испарителя, т.е. от скорости напыления. Кристаллы хлористого калия, используемые в качестве подложек, скалывались по плоскости спайности (001) на воздухе и помещались в вакуумную камеру на нагревательный элемент. Пластины сапфира, выращенные по плоскости (0001), подвергались тщательной полировке, отжигу и дополнительной очистке путем нагрева в вакууме.

Осадок золота на хлористом калии закреплялся углеродной пленкой ( 10-12 nm), отделялся путем растворения кристалла в воде и просматривался в электронном микроскопе (JEOL JSM-6000PLUS Neoscope II). Осадок золота на сапфире просматривался в сканирующем зондовом микроскопе „Интегра-Прима“ фирмы „NT-MDT“.
Использовался режим фазового контраста, с помощью которого можно было разделить изображение поверхности подложки и наноостровков золота.

На ранних стадиях при скорости осаждения золота $\sim 1 \mathrm{~nm} / \mathrm{min}$ до достижения средней толщины слоя $1.5 \mathrm{~nm}$ на поверхности (001) хлористого калия, находящейся при температуре $450 \mathrm{~K}$, плотность наноостровков и их размеры не зависят от наличия ионов в потоке пара золота. При этом плотность наноостровков находится в состоянии насыщения: $\sim 5 \cdot 10^{11} \mathrm{~cm}^{-2}$. Существенное различие осадков наблюдается в процессе увеличения средней толщины слоя от $2 \mathrm{~nm}$ при сохранении скорости осаждения $\sim 1 \mathrm{~nm} / \mathrm{min}$. На рис. 1 приведены изображения осадков со средней толщиной $3.5 \mathrm{~nm}$, полученных при удалении из потока пара ионов $(a)$ и при наличии ионов $(b)$. Наличие ионов в осадке способствует на этой стадии роста значительной коалесценции наноостровков, сопровождающейся их увеличением и снижением плотности на порядок величины. Удаление ионов из осадка замедляет рост наноостровков. На рис. 2, $a$ приведены зависимости плотности островков от времени
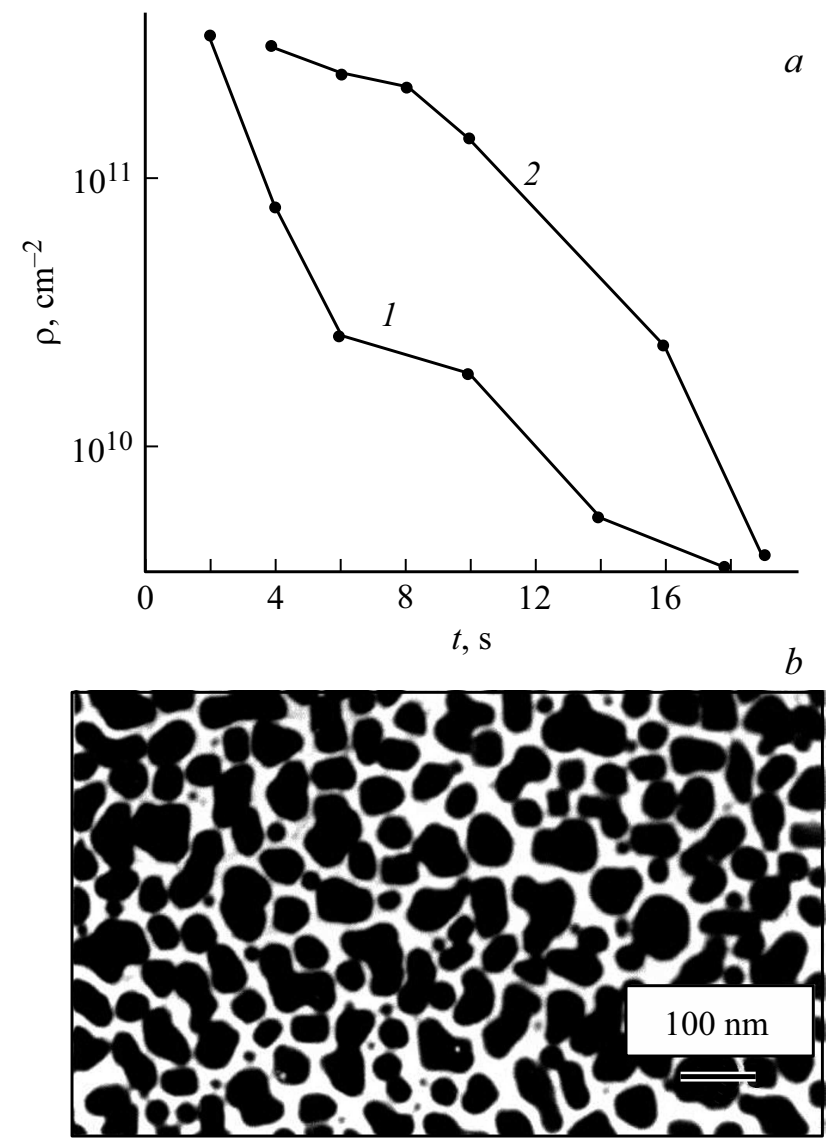

Рис. 2. $a-$ - зависимость плотности островков $\mathrm{Au}$ на (001) $\mathrm{KCl}$ при $T=470 \mathrm{~K}$ от времени напыления золота (скорость осаждения $0.4 \mathrm{~nm} / \mathrm{s}) .1$ - при наличии в потоке $\mathrm{Au}$ ионов, 2 - при удалении ионов. $b$ - электронно-микроскопическое изображение осадка золота толщиной $15 \mathrm{~nm}$, нанесенного в режиме удаления ионов из осаждаемого потока. 
напыления золота на $(001) \mathrm{KCl}$ при наличии ионов и при их удалении из пара, полученные при скорости осаждения $0.4 \mathrm{~nm} / \mathrm{s}$. При толщинах осадка свыше $\sim 8 \mathrm{~nm}$ эта разница нивелируется (рис. $2, b$ ), т. е. наноостровки, в которых отсутствуют заряды, также коалесцируют, их плотность также снижается.

Важно отметить декорирование наноостровками золота ступеней вицинального скола хлористого калия (рис. $1, a, b)$, которое наблюдается как в случае удаления ионов из пара, так и при их наличии. Наблюдаемый эффект объясним, если иметь в виду электростатическое взаимодействие диффундирующих наноостровков со ступенями, проявляющими себя как электрически активная граница. Об исследовании электрической структуры ступеней на поверхностях диэлектрических кристаллов методом фотоэдс сообщалось ранее [12]. В то же время на поверхности кристаллов могут существовать различные электрически активные области. К ним относятся дислокационные выходы на поверхности, а также границы скоплений дефектов (примесей). По всей видимости, на террасах протяженных ступеней свежих сколов хлористого калия имеется высокая плотность электрически активных дефектов, на которых наравне со ступенями закрепляются наноостровки.

Аналогичное поведение осадка наблюдается и при росте золота на сапфире (рис. 3, $a, b$ ) при $570 \mathrm{~K}$. Съемка проводилась в режиме фазового контраста, который позволяет визуализировать изображение наноостровков на рельефной поверхности. Наноостровки золота декорируют ребра террасно-ступенчатой наноструктуры сапфира при осаждении. Видно, что наноостровки на террасах ступеней отсутствуют в отличие от случая осаждения золота на свежие сколы хлористого калия. По-видимому, многостадийная обработка подложек сапфира, включающая стадии полировки, отмывки и высокотемпературного отжига, приводящего к рекристаллизации поверхности, способствует нейтрализации электрически активных дефектов на сверхгладких террасах ступеней. В то же время ступени, являясь линейным дефектом структуры, сохраняют электрическую активность.

Морфологическую перестройку осадка при увеличении средней толщины слоя от $2 \mathrm{~nm}$ можно объяснить кулоновским взаимодействием между наноостровками. При высокой плотности зарядов их перераспределение между наноостровками происходит статистически. Силу взаимодействия между сферическими наноостровками с радиусами $r_{1}$ и $r_{2}$, несущими заряды $q_{1}$ и $q_{2}$ и разделенными расстоянием $a$, с учетом сил электростатического изображения можно представить следующим образом [13]:

$$
F=\frac{q_{1} q_{2}}{4 \pi \varepsilon_{0} a^{2}}-\frac{q_{1}^{2} r_{2} a}{4 \pi \varepsilon_{0}\left(r_{1}^{2}-a^{2}\right)^{2}}-\frac{q_{2}^{2} r_{1} a}{4 \pi \varepsilon_{0}\left(r_{2}^{2}-a^{2}\right)^{2}}+\ldots
$$

При условии, что один из зарядов будет намного больше, или когда размер наноостровков сравним с расстоянием

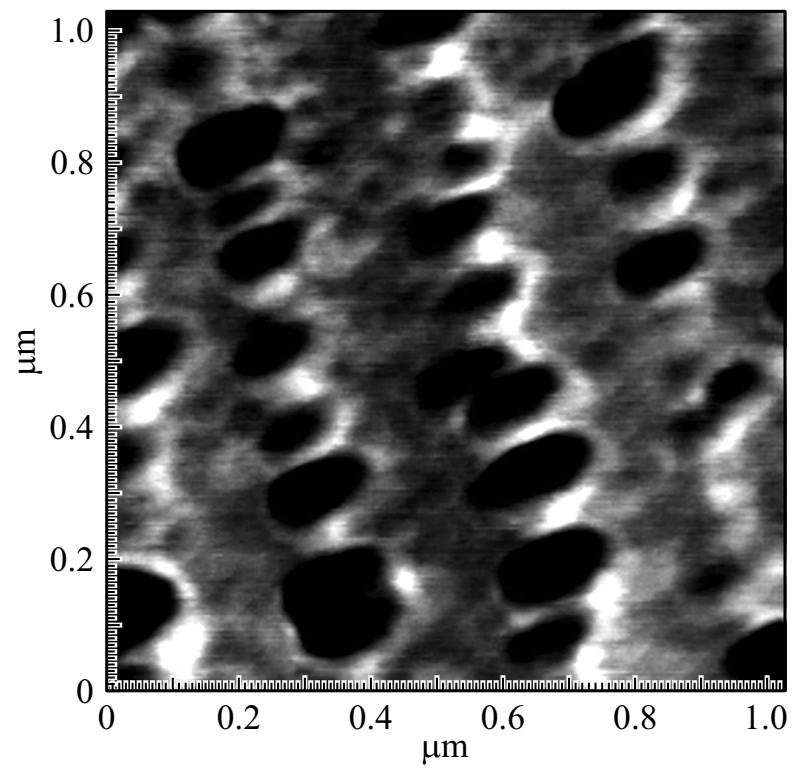

$a$

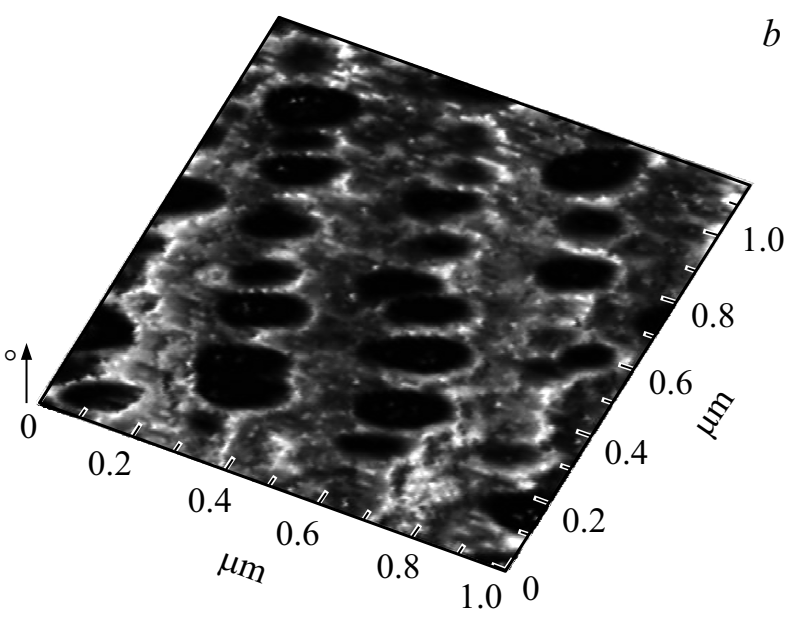

Рис. 3. Полученные с помощью атомно-силовой микроскопии изображения (режим фазового контраста) осадка золота на поверхности подложки (0001) сапфира с террасно-ступенчатой наноструктурой поверхности при $T=570 \mathrm{~K}$. $a$ - двумерное изображение, $b$ - трехмерное изображение.

между ними, последние два члена, описывающие притяжение, будут превосходить первый член, описывающий взаимное кулоновское расталкивание. Предел упругости для кристаллических материалов находится в интервале $10-10^{5} \mathrm{~N} / \mathrm{cm}^{2}$, что достижимо при взаимодействии малого наноостровка с большим и их коалесценции.

Предлагаемая модель взаимодействия заряженных наноостровков на подложке представляет собой упрощение реальных процессов, вызывающих коалесценцию. Необходимо рассматривать коллективное взаимодействие наноостровков и влияние подложки. Наблюдения роста осадка показывают, что один акт коалесценции двух наноостровков вызывает процесс коалесценции соседних наноостровков. Это можно объяснить нарушением равновесия электростатических сил. В процессе 
роста островков заряд на них пропорционально увеличивается и в итоге стекает через поверхность подложки.

Тот факт, что в отсутствие зарядов коалесценция наноостровков протекает на более поздней стадии, позволил предположить наличие упругих сил их взаимодействия. Следует обратить внимание на возможность действия сил Казимира, которая детально изложена в обзоре [14]. Эффект заключается в наличии квантовой электромагнитной энергии нулевых колебаний. Так, на единицу площади двух проводящих плоскопараллельных пластин, находящихся на расстоянии $a$, сила притяжения $F=\left(\pi^{2} / 240\right)\left(h c / a^{4}\right)$. Для пластин площадью $1 \mathrm{~cm}^{2}$ при $a=0.5 \mu \mathrm{m}$ экспериментально определена $F \approx 0.2 \cdot 10^{-5} \mathrm{~N}$, что совпадает с вычисленной величиной. Для проводящих сферических наноостровков радиуса $r$ вычислена их энергия $\Delta E(r) \cong 0.09 h c / 2 r$ [15]. Нельзя отрицать и действие других сил, например обусловленных полями напряжения.

Таким образом, в работе экспериментально изучены процессы взаимодействия наноостровков золота при осаждении из пара в вакууме. Обнаружена зависимость поведения диффундирующих по поверхности подложки наноостровков от заряда в осаждаемом паре. В присутствии заряда слияние наноостровков золота и резкое увеличение их размеров наблюдаются по достижении толщины $\sim 2 \mathrm{~nm}$. При удалении заряда на этой стадии наблюдается замедление роста наноостровков. В экспериментах с использованием подложек с развитой поверхностью обнаружена корреляция морфологии осадка с элементами геометрического рельефа поверхности.

Работа выполнена при поддержке Министерства науки и высшего образования РФ в рамках выполнения работ по государственному заданию ФНИЦ „Кристаллография и фотоника“ РАН в части „получения исследовательских образцов“ и при поддержке Российского фонда фундаментальных исследований (грант 16-29-11763) в части „обсуждения модели поведения наноостровков“ с использованием оборудования ЦКП ИК РАН „Структурная диагностика материалов“.

\section{Список литературы}

[1] Анищик В.М., Борисенко В.Е., Жданок С.А., Толочко Н.К., Федосюк В.M. Наноматериалы и нанотехнологии. Минск: Изд. центр БГУ, 2008. 375 с.

[2] Старостин В.В. Материалы и методы нанотехнологии. М.: Бином, 2008. 432 с.

[3] Ремпель А.А. // Успехи химии. 2007. Т. 76. № 5. C. $474-500$.

[4] Френкель Я.И. Кинетическая теория жидкостей. М.: Издво АН СССР, 1945. 425 c.

[5] Kardovsky A.V., Anashkina E.I., Chichiginaet O.A., Valenti D., Spagnolo B. // J. Stat. Mech. 2016. N 3. P. 033211.

[6] Rhodin T.N., Walton D. Nucleation and growth process in solid surface. Park Ohio, 1963. 259 p.

[7] Darling D.F., Fild D.O. // Surf. Sci. 1972. V. 32. P. 147-152.
[8] Einax M., Dieterich W., Maass Ph. // Rev. Mod. Phys. 2013. V. 85. P. 921-939.

[9] Perez A., Bardotti L., Prevel B. // New J. Phys. 2002. V. 4. P. $1-12$.

[10] Zanghi J.C., Métois J.J., Kern R. // Phil. Mag. A. 1975. V. 31. P. 743-755.

[11] Муслимов А.Э., Асадчиков В.Е., Буташин А.В., Власов В.П., Дерябин А.Н., Рощин Б.С., Сульянов С.Н., Каневский В.М. // Кристаллография. 2016. Т. 61. № 5. C. 709-717.

[12] Айрапетов А.Ш., Власов В.П., Чудаков В.С. // ФТТ. 1976. T. 18. B. 3. C. $1258-1261$.

[13] Dove D.B. // J. Appl. Phys. 1964. V. 35. P. 2785-2786.

[14] Мостепаненко В.М., Трунов Н.Я. // УФН. 1988. Т. 156. № 3. C. $385-426$.

[15] Boyer T.H. // Phys. Rev. 1968. V. 174. P. 1764-1776. 